\title{
Anger and substance abuse: a systematic review and meta-analysis
}

\author{
Helen V. Laitano, ${ }^{1,2}$ iD Amanda Ely, ${ }^{1,2}$ Anne O. Sordi, ${ }^{1}$ Felipe B. Schuch, ${ }^{3}$ iD Flavio Pechansky, ${ }^{1}$ \\ Thiago Hartmann, ${ }^{1}$ Juliana B. Hilgert, ${ }^{1}$ Eliana M. Wendland, ${ }^{4}$ Lisia Von Dimen, ${ }^{1}$ Juliana N. \\ Scherer, ${ }^{1}$ Alessandra Mendes Calixto, ${ }^{1}$ Joana C.M. Narvaez, ${ }^{4}$ Felipe Ornell, ${ }^{1}$ Félix H.P. Kessler ${ }^{1}$ iD \\ ${ }^{1}$ Centro de Pesquisa em Álcool e Drogas, Universidade Federal do Rio Grande do Sul (UFRGS), Porto Alegre, RS, Brazil. ${ }^{2}$ Serviço de \\ Psicologia, Hospital de Clínicas de Porto Alegre (HCPA), Porto Alegre, RS, Brazil. ${ }^{3}$ Departamento de Métodos e Técnicas Desportivas, \\ Universidade Federal de Santa Maria (UFSM), Santa Maria, RS, Brazil. ${ }^{4}$ Universidade Federal de Ciências da Saúde de Porto Alegre \\ (UFCSPA), Porto Alegre, RS, Brazil.
}

\begin{abstract}
Objective: Conduct a systematic review and meta-analysis to evaluate levels of anger among substance users compared to non-user controls and to analyze the possible association between anger and psychoactive substance use (PSU).

Methods: The procedures of this review followed the Meta-Analyzes of Observational Studies in Epidemiology (MOOSE) and Preferred Reporting Items for Systematic Reviews and MetaAnalyses (PRISMA) guidelines. Four electronic databases (MEDLINE, EMBASE, BIREME, PsycINFO) were searched.

Results: Twelve studies were included in the meta-analysis; 10 used the State-Trait Anger Expression Inventory (STAXI) anger trait subscale and two used the Buss-Perry-Aggression Questionnaire (BPAQ) anger subscale. The sample included 2,294 users of psychoactive substances and 2,143 nonusers, all male. The mean difference in anger scale scores between users and non-users was 2.151 $\left(95 \% \mathrm{Cl} 1.166-3.134, \mathrm{p} \leqslant 0.00\right.$, inconsistency index $\left.\left[\mathrm{I}^{2}\right]=98.83\right)$ standard deviations. Age and abstinence duration did not moderate the difference in anger between substance users and non-users. Conclusion: Users of psychoactive substances had elevated anger scores compared to non-users, which represents a high risk of relapse. It is suggested that PSU treatment programs include intensive anger management modules, focusing on factors such as dealing with daily stressors, family conflicts, frustrations, and problems.
\end{abstract}

Keywords: Substance use disorder; substance use; drug use; anger

\section{Introduction}

Anger may be linked to the psychoactive substance use (PSU) process. ${ }^{1}$ Previous investigations have shown that drug users have especially high anger scores compared to non-users. ${ }^{2,3}$ Usually, anger is considered part of an adaptive emotional response triggered by environmental stimuli that are essential to establishing quick and essential reactions to preserve life. The level of intensity can vary in the way the stimulus is perceived, sometimes interpreted as a threat and frustration. ${ }^{4,5}$ Neuronal and physiological changes resulting from anger, when added to PSU, can compromise attention, information abstraction, activities that involve planning, problem solving, and emotional regulation..$^{6-8}$ Consequently, anger can impair decision making and prompt dysfunctional behavioral responses. $^{9-11}$

Correspondence: Helen V. Laitano, Serviço de Psicologia, Hospital de Clínicas de Porto Alegre (HCPA), Rua Ramiro Barcelos, 2350, CEP 90035-903, Porto Alegre, RS, Brazil.

E-mail: helenlaitano@gmail.com

Submitted May 15 2020, accepted Oct 19 2020, Epub Feb 102021.
Concomitant use of multiple psychoactive substances alters neurobiological metabolism with regards to their overlapping effects. ${ }^{12}$ An example of this is the combined use of cocaine and alcohol. Taken together, these two substances are metabolized in the liver to form cocaethylene, which has longer-lasting effects than either substance taken alone. Most people who use cocaine together with central nervous system depressants (alcohol, benzodiazepines, marijuana, and opioids) aim to combat the drug's sympathomimetic effects. Frequent and intense use can cause changes in behavior, emotions, and cognition. These changes include excitability, irritability, aggressiveness, depression, slowness in thinking, and concentration. There is a greater susceptibility to physical aggression, suicide, homicide, and other incidents of violence. ${ }^{3,13-16}$

Although previous investigations have explored the association of anger with PSU, there are few studies that

How to cite this article: Laitano HV, Ely A, Sordi AO, Schuch FB, Pechansky F, Hartmann T, et al. Anger and substance abuse: a systematic review and meta-analysis. Braz J Psychiatry. 2022;44:103-110. http://dx.doi.org/10.1590/1516-4446-2020-1133 
address aspects of trait anger between users and non-users of psychoactive substances. ${ }^{17}$ The frequent and intense anger observed in users of psychoactive substances in clinical treatment has been considered a risk factor for relapse. ${ }^{18-22}$ Within this context, the main objective of the present study is to understand, through a systematic review and meta-analysis, the relationship between anger scores in patients using psychoactive substances and non-user controls, including possible moderators such as age, sex, and withdrawal time. The practical reasons for conducting this study are to assess whether it is relevant to include this feeling in therapeutic practices with users of psychoactive substances and determine which symptoms correlate with anger.

\section{Methods}

This review followed the Meta-Analyses of Observational Studies in Epidemiology (MOOSE) and Preferred Reports Items for Systematic Reviews and Meta-Analyses (PRISMA) guidelines. ${ }^{22,23}$

\section{Eligibility criteria}

Only studies with observational analytical designs (prospective, case-control, or cross-sectional cohort studies) were eligible.

Studies that compared trait and state anger between substance users and non-users were included. Psychoactive substance users was described in the studies according to clinical evaluation based on the DSM-III and DSM-IV criteria for substance use disorder.

The State-Trait Anger Expression Inventory (STAXI) ${ }^{4}$ consists of 57 items, which are grouped into scales and subscales, divided into subgroups (anger state, anger trait, anger expression, and anger control). ${ }^{23}$ For the present study, only measurements of the anger trait subscale (consisting of 10 items, and further divided into angry temperament) were considered. The STAXI was used and evaluated in 10 studies.

The Buss-Perry-Aggression Questionnaire (BPAQ) ${ }^{24}$ consists of 29 items, subdivided into four factors (which resulted from factor analysis): physical aggression (nine items); verbal aggression (four items); anger (six items); and hostility (seven items). In this study, only the anger subscale was considered.

According to the concept of anger based on the STAXI and BPAQ, trait anger assesses a person's general predisposition to be angry. The T-Ang subscales measure whether people have a general temperament containing anger or tend to respond with anger when they feel they are being treated unfairly, are criticized by others, or feel frustrated. Trait anger is one of the central variables of STAXI-2, and is critical to understanding how often a person becomes irritated in various situations. Buss-Perry Aggression anger is associated with irritation and vulnerability to stress, with a similar concept to the anger trait on the STAXI scale. ${ }^{25,26}$

\section{Study selection and data extraction}

The search was conducted by two independent authors (HVL and AE) who first analyzed the titles and abstracts and then selected manuscripts for full-text reading. Disagreements regarding inclusion in the study were resolved through discussion with a third author (FHK) until a consensus was reached. The reference lists of all included studies were also hand-searched for other relevant articles.

The following databases were searched: MEDLINE (via PubMed); Biomedical Research (EMBASE); the Latin-American and Caribbean Health Sciences Literature database (BIREME); and the Psychological Abstracts databases (PsycINFO). Articles published by the end of January 2020 were eligible. The search queries were Alcohol OR cocaine, OR heroin, marijuana, OR inhalants, OR tobacco, OR substance use, OR substance addiction, OR drug dependence AND Anger. This extensive electronic database search was supplemented by a search of theses and dissertations, abstracts, expert consultations, and a review of relevant documents to identify any additional studies in the field, in an attempt to minimize publication bias. Ada Johansson, the author of one included study, was contacted and responded with additional information about anger scores that were not reported in the manuscript. ${ }^{14}$

\section{Data extraction}

A standardized data extraction form was used to record the following information about each article: authors, year of publication, country, scenario, study design, sample size, age group of the sample, strategy used for classification, and result of interest (extracted as average standard deviation [SD] for users and non-users).

As noted above, the mean (M) and SD scores for anger among users and non-users of psychoactive substances, assessed by the $\mathrm{STAXI}^{4}$ and $\mathrm{BPAQ}^{24}$ instruments, were collected and recorded.

The Newcastle-Ottawa Scale (NOS) was used to assess the quality of non-randomized studies. The star system was developed from three broad perspectives: the selection of study groups; the comparability of groups; and the verification of the exposure or outcome of interest for observational studies. Its objective is directed at the task of incorporating quality in the interpretation of metaanalytical results. ${ }^{27}$

\section{Statistical analysis}

The difference in the total mean scores of the STAXI anger trait subscale and the BPAQ (anger subscale) between users and non-users was quantified using the standardized mean difference (SMD). A random model was used due to the anticipated high heterogeneity, which was measured by $p$-value estimates for Cochrane's Q-test and by the inconsistency index $\left(\mathrm{I}^{2}\right)$, which was used to pool the effects of individual studies. Values equal to or greater than $50 \%$ were indicative of significant variances in the effects between studies. 
The heterogeneity was explored using: 1) meta-regressions, in the role of age, gender (male and female), and depressive symptoms as moderators of the difference; subgroup analyzes of sex and drug type; and 3) a sensitivity analysis removing the studies with effects exceeding the second SD. Comprehensive Meta-Analysis (CMA) software was used. We evaluated publication bias through visual inspection of the funnel plot and using the Begg \& Mazumdar ${ }^{28}$ and Egger tests, ${ }^{29}$ and corrected for this bias using the Duval \& Tweedie trimand-fill method. ${ }^{30}$

\section{Results}

\section{Systematic review and meta-analysis}

Figure 1 and Table 1 show a summary of the 12 studies included in the systematic review and meta-analysis of the literature. The design of all identified studies was cross-sectional. Women were not included, because only four of the 12 studies presented complete data on women's anger scores. Data from 4,437 men were obtained. The average age of the men was 26.4 years old, $50 \%$ were undergoing treatment for the PSU, $20 \%$ participated in laboratory studies, $10 \%$ were university students, $10 \%$ were in the prison system, and $10 \%$ were part of the general population. The time without PSU in the hospital was 14,21 , and 28 days. Within the therapeutic community, it was 48 and 95 days. In the laboratory, it was 1 and 2 days. In other studies, patients were under the effects of PSU. The psychoactive substances described in the studies were alcohol, cocaine, khat, marijuana, heroin, and multiple substances.

The search flowchart and selection procedures are shown in Figure 1. All 12 studies included in the final selection are summarized in Table 1.

The studies were carried out in the United States, Brazil, Turkey, Saudi Arabia, Canada, Italy, Finland, and Hungary. The STAXI scales were used in 10 studies $^{18,26,40-49}$ and the BPAQ in the other two studies. ${ }^{26,40}$

Substance users had higher anger levels compared to non-users (Figure 2) $(\mathrm{SMD}=2.151 ; 95 \%$ confidence interval $[95 \% \mathrm{Cl}] 1.16$ to $3.14, \mathrm{p}<0.001)$. A forest plot is shown in Figure 2. The variability of effects across the included studies was high, resulting in high heterogeneity $\left(1^{2}=98.8 \%\right)$.
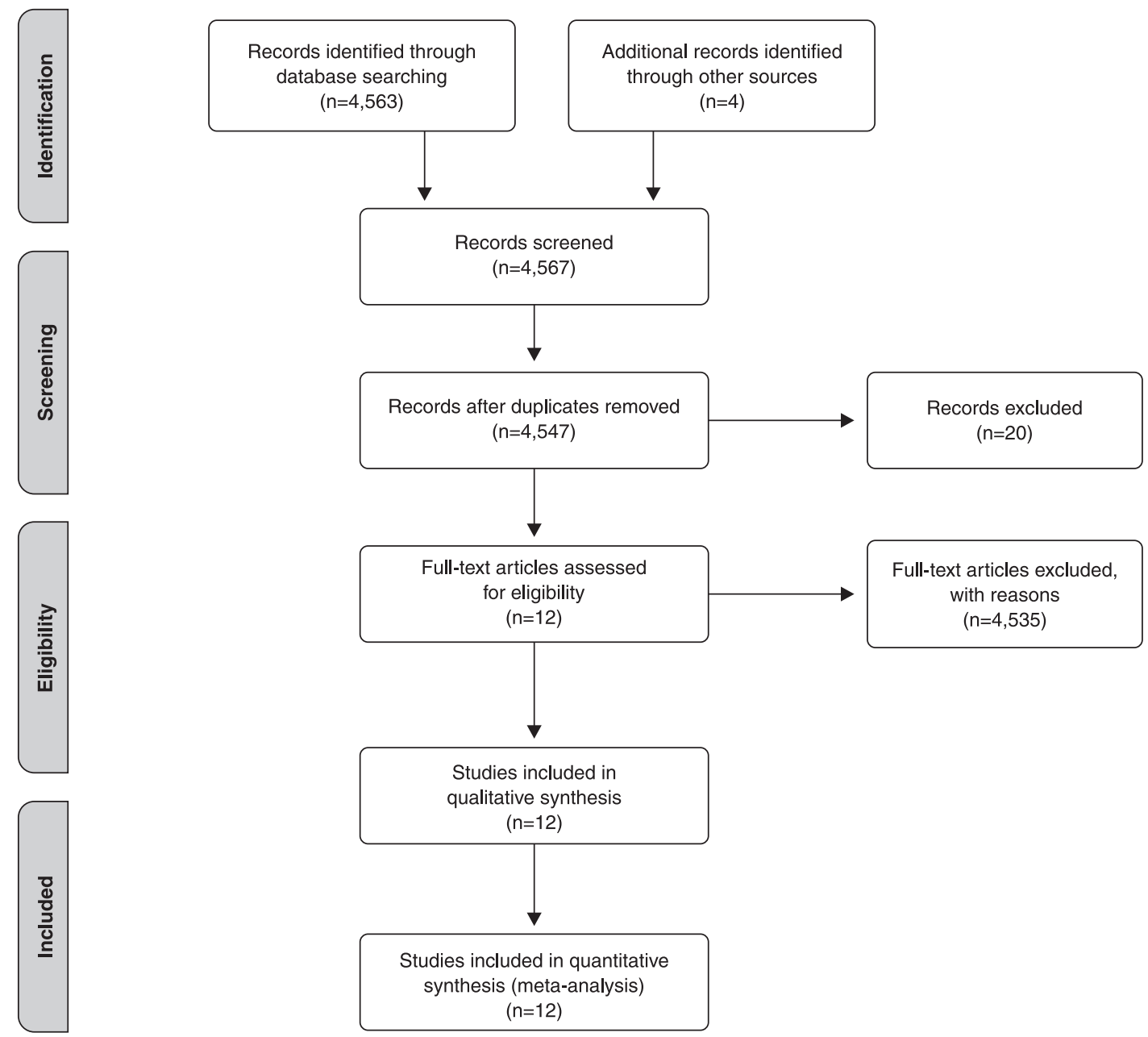

Figure 1 PRISMA flow diagram of systematic review and meta-analysis. 
Table 1 Characteristics of the included studies (non-users and users of psychoactive substances, mean and standard deviation [SD] of anger scores, type of substance, duration of abstinence, and setting)

\begin{tabular}{|c|c|c|c|c|c|c|c|}
\hline \multirow[b]{2}{*}{ Study } & \multicolumn{2}{|c|}{ Non-users } & \multicolumn{2}{|c|}{ Users } & \multirow[b]{2}{*}{ Substance } & \multicolumn{2}{|c|}{ Duration of abstinence } \\
\hline & $\mathrm{n}$ & Mean (SD) & $\mathrm{n}$ & Mean (SD) & & Maximum (days) & Setting \\
\hline Bongard $^{31}$ & 21 & $20.95(5.83)$ & 42 & 23.37 (5.95) & Khat & 1 & Turkey \\
\hline Lemieux $^{32}$ & 25 & $20.56(4.51)$ & 38 & $22.13(5.37)$ & Khat and tobacco & 2 & Arabia \\
\hline Schonwetter ${ }^{33}$ & 51 & $19.3(0.7)$ & 111 & $22.9(0.5)$ & Alcohol & Actively intoxicated & Canada \\
\hline Tivis $^{34}$ & 36 & $14.7(4.07)$ & 70 & $19.26(4.83)$ & Alcohol & 21 & United States \\
\hline De Mojá ${ }^{18}$ & 30 & $18.11(4.83)$ & 30 & 22.01 (4.99) & Heroin & Actively intoxicated & Italy \\
\hline Scheffer ${ }^{35}$ & 17 & $15.88(3.19)$ & 17 & $17.47(4.55)$ & Crack/cocaine & 95 & Brazil \\
\hline Bozkurt $^{36}$ & 63 & $8.18(5.11)$ & 94 & $11.38(6.57)$ & Alcohol & 28 & Turkey \\
\hline Almeida $^{37}$ & 25 & $16.08(3.62)$ & 25 & $22.56(6.17)$ & Multiple substances & 60 & Brazil \\
\hline Çorapçıoğlư & 124 & $17(6.1)$ & 82 & $20(6.4)$ & Alcohol & Actively intoxicated & Turkey \\
\hline Johansson ${ }^{14}$ & 1,653 & $1.7(0.42)$ & 1,513 & $2.58(0.33)$ & Alcohol & Actively intoxicated & Finland \\
\hline Bácskai $^{39}$ & 212 & $13.93(0.51)$ & 101 & $20.45(0.58)$ & Alcohol & 28 & Hungary \\
\hline Aharonovich $^{40}$ & 37 & $18.52(4.8)$ & 20 & $21(6.7)$ & Cocaine & 14 & United States \\
\hline
\end{tabular}

$\mathrm{SD}=$ standard deviation.

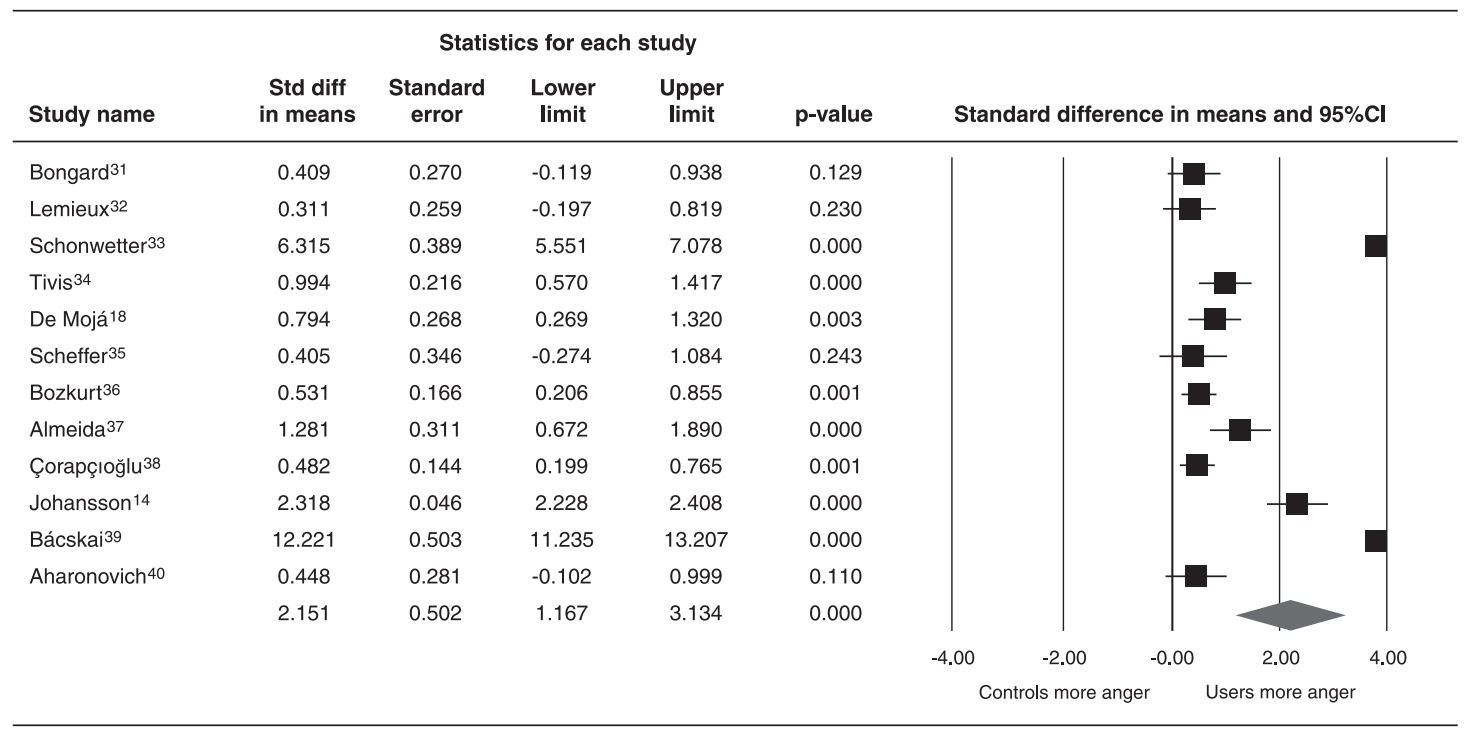

Meta-analysis

Figure 2 Meta-analysis: comparison of anger levels between users and non-users of psychoactive substances. $95 \% \mathrm{Cl}=95 \%$ confidence interval.

\section{Meta-regressions}

Depressive symptom severity was associated with higher anger levels (coefficient $=-0.1546,95 \% \mathrm{Cl} 0.8661$ to $\left.0.5570, p=0.6703, R^{2}=0.80\right)$. Sex and age did not moderate this difference.

\section{Sensitivity analysis}

The sensitivity analysis was performed using two effects from the Bácskai $^{39}$ study and one effect from the Schonwetter ${ }^{33}$ study. In this analysis, heterogeneity dropped to $61 \%$. The recalculated effect size is 8.58 .

\section{Subgroup analyses}

In all subgroups of psychoactive substances there, was an increase in anger scores among users: alcohol, crack, and cocaine (effect size $11.8,95 \% \mathrm{Cl} 10.6$ to 13.05); alcohol (effect size $2.22,95 \% \mathrm{Cl} 1.59$ to 2.85 ); crack and cocaine (effect size $0.62,95 \% \mathrm{Cl}-0.13$ to 1.37 ); heroin (effect size $0.62,95 \% \mathrm{Cl}-0.14$ to 1.39 ); khat (effect size $0.46,95 \% \mathrm{Cl}-0.23$ to 1.17 ); and marijuana (effect size $1.19,95 \% \mathrm{Cl}-0.28$ to 2.67$)$.

\section{Quality assessment}

Study quality was assessed by the same two reviewers including lead author (HVL) and (TH) using the NOS for cross-sectional design $^{42}$ (Table 2).

\section{Discussion}

This is the first time a meta-analysis has demonstrated that psychoactive substance users have higher trait anger scores than non-user controls. Furthermore, the intensity of anger was independent of age and duration of 
Table 2 Quality of studies according to the Newcastle-Ottawa scale (NOS) for observational studies adapted for crosssectional studies

\begin{tabular}{|c|c|c|c|c|}
\hline Study & Selection & Comparability & Result & Total \\
\hline Bongard $^{31}$ & $* * *$ & $* * *$ & $* * *$ & 9 \\
\hline Lemieux $^{32}$ & $* * *$ & $* * *$ & $* * *$ & 9 \\
\hline Schonwetter ${ }^{33}$ & $* * * *$ & $* *$ & $* *$ & 8 \\
\hline Tivis $^{34}$ & $* * * *$ & $* *$ & $*$ & 7 \\
\hline Mojá $^{18}$ & $* *$ & $* *$ & $* *$ & 6 \\
\hline Scheffer ${ }^{35}$ & $* * *$ & $*$ & $* *$ & 6 \\
\hline Bozkurt $^{36}$ & $* * * *$ & $* *$ & $* *$ & 8 \\
\hline Almeida $^{37}$ & $* * *$ & $* *$ & $* * *$ & 8 \\
\hline Çorapçıoğlu 38 & $* * * *$ & $* *$ & $* *$ & 8 \\
\hline Johansson $^{14}$ & $* * * *$ & $* * *$ & $* *$ & 9 \\
\hline Aharonovich $^{40}$ & $* * *$ & $* * *$ & $*$ & 7 \\
\hline Báskai $^{39}$ & $* * *$ & $* * *$ & $* * *$ & 9 \\
\hline
\end{tabular}

Assessment of study quality according to the Newcastle-Ottawa scale for observational studies. Scores range from 0 to 9: cross-sectional studies with scores of 7 and 9 were considered good, 4 and 6 stars moderate, and those with 3 stars or fewer as low quality.

abstinence. These results are in line with studies that showed high levels of anger in substance-dependent subjects $^{39}$ and which estimated that this anger may be chronic. This is essential for developing more effective, targeted therapies, such as emotional regulation programs focused on anger management. Several factors need to be considered in interpreting these results, such as: the relationship of anger with psychiatric comorbidities, traumatic stress during childhood and adolescent development, personality and temperament features; our understanding of the neurobiological apparatus of emoticons and its relationship with neuroadaptation of the brain secondary to PSU; the type of substance used; the timing of anger measurement - whether during active use or abstinence/withdrawal; and the frequency of use. $33,50,51$

Drug users appear to experience anger more often and more intensely than non-users. This may be attributable to several factors. First, it is worth stressing that the causal chain involving anger and drugs is complex. Studies have reported that intensity of anger is predictive of drug use. ${ }^{52}$ The literature review cited above highlights the need to examine how anger is defined and how its association with substance use is measured. Distinct forms of anger are recognized in the literature: 1) frequent, intense personality traits of irritation when faced with diverse situations, also known as trait anger ${ }^{53}$; and 2) momentary anger in response to specific situations, also known as state anger. ${ }^{54}$ Both the STAXI scale and the BPAQ use these concepts. ${ }^{55}$ The BPAQ correlates with STAXI in trait anger. ${ }^{56}$

Anger and anxiety can be experienced as symptoms of craving, as part of the desire to obtain the pleasurable sensation associated with PSU. ${ }^{57}$ Anger can also be understood as a result of long-term changes in the brain that result in the emergence of a negative emotional state, or withdrawal symptoms. Abrupt discontinuation of longterm illicit opioid and crack-cocaine use can produce withdrawal symptoms as early as hours after the most recent use. Initial symptoms of anxiety, agitation, and restlessness are distressing to patients, which may lead to increased irritability and aggression. ${ }^{58}$ Abstinence in alcohol users after treatment is different, as there is no evidence of urgency of use as is seen with substances such as heroin and crack-cocaine. This can be related to several factors, but those most described in the literature are emotional aspects linked to negative affects that trigger a craving for alcohol use. ${ }^{59}$ These neuroadaptive modifications involve dynamic readjustments toward a new set point. This causes an imbalance in the reward system and failure to experience pleasure with natural stimuli, reinforcing and increasing the likelihood of reacting to negative emotional cues with anger, anxiety, and depression. ${ }^{43,45}$

Psychiatric conditions such as anxiety, depression, and impulsivity are very prevalent in this population. ${ }^{46}$ The results of this study showed a significant relationship in the group of users of psychoactive substances with depressive symptoms, and higher anger scores. Although there were few studies, users with 14-21 days of abstinence who experienced depressive symptoms had higher anger scores than non-users. There is a strong link in the literature between depressive symptoms and anger reactions. ${ }^{60}$ In a 1-day withdrawal study, symptoms of depression and anger may be related to a lack of the psychoactive substance or a desire to use the substance. The discomfort generated by these symptoms also serves as a trigger for self-medication, i.e., PSU, in an attempt to self-regulate the suffering caused by the negative mental state. ${ }^{61}$ Individuals can develop psychiatric problems throughout life due to pharmacological effects of chronic drug use on the brain. ${ }^{62}$ Thus, anger can precede PSU, but it can also be intensified by chronic PSU and concomitant psychiatric conditions. Another factor to be addressed is that repeated exposure to psychoactive substances leads to changes in the regions of the brain associated with learning, inhibitory control, reward and motivation, and executive function. ${ }^{32,37}$ These changes can increase the reactivity to stress in the presence of emotional states and reduce the capacity for emotional self-regulation - aspects closely related to anger. This could explain, at least in part, why drug users seem to have less control and are more likely to express anger towards other people or objects. ${ }^{40}$

In psychiatric disorders such as anxiety and depression, the tendency is for symptoms to decrease with treatment and prolonged abstinence from PSU. ${ }^{63} \mathrm{How}-$ ever, surprisingly, there was no difference in anger scores 
in different contexts and abstinence times: patients undergoing treatment for 14 to 28 days without using psychoactive substances (alcohol, cocaine, and heroin dependence); incarcerated patients intoxicated with alcohol; intoxicated individuals drawn from the general community in Finland; patients on a university campus with 1 day of abstinence from khat; patients in therapeutic communities with 60 to 95 days of abstinence from alcohol, tobacco, cocaine, crack, and multiple substances; and university undergraduate students intoxicated with alcohol. The hypothesis is that symptoms may actually worsen in the first 1-2 days due to lack of the psychoactive substance, increasing craving, reactivity to negative effects, and stress, and, consequently, increasing anger, which can increase the likelihood of relapse and interfere with prognosis. ${ }^{64}$ In patients with 14 to 95 days of abstinence, anger can be a serious and lasting problem, with a link between personality traits and daily episodes of anger. ${ }^{65}$

Still considering the changes in the brain induced by PSU, dopaminergic dysfunction in reward circuits seems to lead to dysfunctions in the orbitofrontal cortex. ${ }^{35}$ This region has been implicated in the impulsivity observed in psychoactive substance users, ${ }^{66}$ as ascertained in many studies in subjects with high anger scores. This is particularly interesting in understanding these results, as the orbitofrontal cortex is anatomically connected to sensory, limbic, and prefrontal cortical regions ${ }^{67}$ - areas affected by drug use and which mediate executive function. ${ }^{68}$ This may be related to the deficits in cognitive processing and decision-making observed in substance users. Prior studies have shown that compulsive drugseeking and relapse are partly mediated by psychoactive substance-induced changes in the orbitofrontal cortex. ${ }^{47,69}$

The literature has shown that anger responses tend to decrease with age, perhaps due to a reduction in neurophysiological reactivity. ${ }^{36,48}$ Still, this appears to be mediated by several psychosocial variables. ${ }^{49}$ It is possible that structural brain changes resulting from chronic drug exposure may interfere with anger experience in an age-independent manner, as cognitive processing and decision-making deficits in this population are well described. ${ }^{70,71}$ In addition, brain changes appear to be long-lasting and related to a breakdown in emotional self-regulation and increased sensitivity to stressful stimuli. ${ }^{72,73}$ Nevertheless, the intensity of the anger experience may differ depending on the drug, age of onset, frequency, and concomitant use of other substances. ${ }^{31,34,74}$ In this study, the subgroup with the largest effect size in relation to anger scales was composed of users of alcohol, cocaine, and crack. The literature reinforces that the simultaneous use of alcohol and cocaine potentiates withdrawal symptoms in the body, including irritation and anger. ${ }^{38,75-78}$

The main limitation of the cross-sectional design of the included studies is that they did not allow for the determination of different anger profiles and the amount of PSU over time. All possible analyses were carried out between anger and depression, anger and type of psychoactive substances, anger and withdrawal time, anger in men and women, anger and age. Anger and depression were significantly correlated, but the number of studies was small.

Importantly, the literature on this subject is still scarce. Studies have been conducted in vastly different treatment settings (inpatient, outpatient, therapeutic communities) and used various types of instruments to assess anger; therefore, we decided to restrict our analysis to those using similar methods, to increase the validity of comparative measurements. This limitation notwithstanding, our review was able to include a relevant sample size ( $>3,000$ participants) in the meta-analysis. The fact that the samples consisted entirely of men also minimized possible gender biases related to hormonal and cerebral issues; conversely, it impedes generalization of our findings to include women. In conclusion, this systematic review and meta-analysis found high levels of anger in users of psychoactive substances. Reducing the intensity and duration of negative affect, stabilizing these symptoms, and developing more functional modes of coping should be the objectives of pharmacological and psychotherapeutic treatment strategies directed at substance users. We suggest that PSU disorder treatment programs include intensive, targeted anger management modules, focusing on such factors as how to deal with daily stressors, family conflicts, frustrations, and problems. Factors related to comorbidities should also be observed and evaluated more judiciously and systematically in future studies.

In conclusion, these original findings reinforce the relevance of the issue of anger management among the population of substance-dependent patients and the increase in anger scores (as measured by the STAXI and BPAQ) among psychoactive substance users. This population is more likely to show trait anger with higher scores, low anger control, high expression of anger, and tendencies towards aggression compared to non-users. These findings are relevant to mapping issues related to PSU and assisting in the development treatment approaches for substance addiction which include anger management as part of relapse prevention.

\section{Disclosure}

The authors report no conflicts of interest.

\section{References}

1 Czermainski FR, Lopes FM, Ornell F, Pinto Guimarães LS, Von Diemen L, Kessler F, Martins de Almeida RM. Concurrent use of alcohol and crack cocaine is associated with high levels of anger and liability to aggression. Subst Use Misuse. 2020;55:1660-6.

2 Kwako LE, Koob GF. Neuroclinical framework for the role of stress in addiction. Chronic Stress (Thousand Oaks). 2017 Feb;1:247054 7017698140. doi: 10.1177/2470547017698140. Epub 2017 Apr 10.

3 Cougle JR, Summers BJ, Allan NP, Dillon KH, Smith HL, Okey SA, et al. Hostile interpretation training for individuals with alcohol use disorder and elevated trait anger: a controlled trial of a web-based intervention. Behav Res Ther. 2017;99:57-66.

4 Forgays DK, Spielberger CD, Ottaway SA, Forgays DG. Factor structure of the State-Trait Anger Expression Inventory for middleaged men and women. Assessment. 1998;5:141-55.

5 Lievaart M, Franken IH, Hovens JE. Anger assesment and clinical and non-clinical populations: further validation of the State-Trait Anger Expression Inventory-2. J Clin Psychol. 2016;72:263-78. 
6 Kalay T, Egeci IS, Ozer S. Turkish adaptation and validation of Spielberger's State Anger Subscale. Global J Psychol Res. 2017;7: 71-80.

7 Garfinkel SN, Zorab E, Navaratnam N, Engels M, Mallorquí-Bagué N, Minati $L$, et al. Anger in brain and body: the neural and physiological perturbation of decision-making by emotion. Soc Cogn Affect Neurosci. 2016;11:150-8.

8 Fernandez E, Johnson SL. Anger in psychological disorders: prevalence, presentation, etiology and prognostic implications. Clin Psychol Rev. 2016;46:124-35.

9 Baharvand P, Malekshahi F. Relationship between anger and drug addiction potential as factors affecting the health of medical students. J Educ Health Promot. 2019;8:157.

10 Okuda M, Picazo J, Olfson M, Hasin DS, Liu SM, Bernardi S, et al. Prevalence and correlates of anger in the community: results from a national survey. CNS Spectr. 2015;20:130-9.

11 Borteyrou X, Bruchon-Schweitzer M, Spielberger CD. [The French adaptation of the STAXI-2, C.D. Spielberger's State-trait anger expression inventory]. Encephale. 2008;34:249-55.

12 Lewis B, Garcia CC, Bohan R, Nixon SJ. Impact of polysubstance use on social and non-affective cognitive performance among treatment-seeking individuals with alcohol use disorders. Addict Behav. 2020;106:106359.

13 Liu Y, Van Den Wildenberg WP, De Graaf, Y, Ames SL, Baldacchino $\mathrm{A}, \mathrm{B} \varnothing \mathrm{R}$, et al. Is (poly-)substance use associated with impaired inhibitory control? A mega-analysis controlling for confounders. Neurosci Biobehav Rev. 2019;105:288-304.

14 Johansson A, Santtila P, Corander J, Jern P, Von der Pahlen B, Varjonen $\mathrm{M}$, et al. Controlling anger in self-reported sober and alcohol intoxicated states: moderating effects of trait anger and alcohol consumption. Scand J Psychol. 2011;52:382-8.

15 Lievaart M, van der Veen FM, Huijding J, Hovens JE, Franken IH. The relation between trait anger and impulse control in forensic psychiatric patients: an EEG study. Appl Psychophysiol Biofeedback. 2018;43:131-42.

16 McCaul ME, Wand GS, Weerts EM, Xu X. A paradigm for examining stress effects on alcohol-motivated behaviors in participants with alcohol use disorder. Addict Biol. 2018;23:836-45.

17 Sharma MK, Suman LN, Murthy P, Marimuthu P. Relationship of anger with alcohol use treatment outcome: follow-up study. Indian $\mathrm{J}$ Psychol Med. 2017;39:426-9.

18 De Mojá CA, Spielberger CD. Anger and drug addiction. Psychol Rep. 1997;81:152-4.

19 Bodkyn CN, Holroyd CB. Neural mechanisms of affective instability and cognitive control in substance use. Int $J$ Psychophysiol. 2019;146:1-19.

20 Kelly JF, Stout RL, Tonigan JS, Magill M, Pagano ME. Negative affect, relapse, and alcoholics anonymous (AA): does AA work by reducing anger? J Stud Alcohol Drugs. 2010;71:434-44.

21 Clarke PB, Lewis TF, Myers JE, Henson RA, Hill B. Wellness, emotion regulation, and relapse during substance use disorder treatment. J Couns Dev. 2020;98:17-28.

22 Chow R, Bruera E, Temel JS, Krishnan M, Im J, Lock M. Inter-rater reliability in performance status assessment among healthcare professionals: an updated systematic review and meta-analysis. Support Care Cancer. 2020;28:2071-8.

23 Van Zuuren, EJ, Fedorowicz Z. Moose on the loose: checklist for meta-analyses of observational studies. Br J Dermatol. 2016;175: 853-4.

24 Buss $\mathrm{AH}$, Perry M. The aggression questionnaire. J Pers Soc Psychol. 1992;63:452-9.

25 Etzler SL, Rohrmann S, Brandt H. Validation of the STAXI-2: a study with prison inmates. Psychol Test Assess Model. 2014;56:178-94.

26 Gallagher JM, Ashford JB. Buss-Perry aggression questionnaire: testing alternative measurement models with assaultive misdemeanor offenders. Crim Justice Behav. 2016;43:1639-52.

27 Cook DA, Reed DA. Appraising the quality of medical education research methods: the medical education research study quality instrument and the Newcastle-Ottawa scale-education. Acad Med. 2015;90:1067-76.

28 Begg CB, Mazumdar M. Operating characteristics of a rank correlation test for publication bias. Biometrics. 1994;50:1088-101.

29 Egger M, Smith GD, Schneider M, Minder C. Bias in meta-analysis detected by a simple, graphical test. BMJ. 1997;315:629-34.
30 Duval S, Tweedie R. Trim and fill: a simple funnel-plot-based method of testing and adjusting for publication bias in metaanalysis. Biometrics. 2000;56:455-63.

31 Bongard S, al'Absi M, Khalil NS, Al Habori M. Khat use and trait anger: effects on affect regulation during an acute stressful challenge. Eur Addict Res. 2011;17:285-91.

32 Lemieux AM, Nakajima M, Saif-Ali R, Al-Habori M, Dokam A, al'Absi M. Anger, anxiety, and depressive affect as predictors of stressinduced cortisol production in khat and tobacco users. Addict Behav. 2018;82:195-201.

33 Schonwetter DJ, Janisse MP. Alcohol consumption, anger and hostility: a link to coronary heart disease. Pers Individ Dif. 1991;12: 1049-55.

34 Tivis LJ, Parsons OA, Nixon SJ. Anger in an inpatient treatment sample of chronic alcoholics. Alcohol Clin Exp Res. 1998;22: 902-7.

35 Scheffer M, Pasa GG, de Almeida RM. Atenção, ansiedade e raiva em dependentes químicos. Psico. 2009;40:235-44.

36 Bozkurt M, Evren C, Yilmaz A, Can Y, Cetingok S. Aggression and impulsivity in different groups of alcohol and heroin dependent inpatient men. Klinik Psikofarmakol Bülteni. 2013;23:335-44.

37 de Almeida RM, Flores AC, Scheffer M. Suicidal ideation, problem solving, expression of anger and impulsiveness in dependents on psychoactive substances. Psicol Reflex Crit. 2013;26:1-9.

38 Çorapçıŏlu A, Erdoğan AS. Cross-sectional study on expression of anger and factors associated with criminal recidivism in prisoners with prior offences. Forensic Sci Int. 2004;140:167-74.

39 Bácskai E, Czobor P, Gerevich J. Gender differences in trait aggression in young adults with drug and alcohol dependence compared to the general population. Prog Neuropsychopharmacol Biol Psychiatry. 2011;35:1333-40.

40 Aharonovich E, Nguyen HT, Nunes EV. Anger and depressive states among treatment-seeking drug abusers: testing the psychopharmacological specificity hypothesis. Am J Addict. 2001;10:327-34.

41 Jones AW. Forensic drug profile: cocaethylene. J Anal Toxicol. 2019;43:155-60.

42 Bae JM. A suggestion for quality assessment in systematic reviews of observational studies in nutritional epidemiology. Epidemiol Health. 2016;38:e2016014.

43 Ruisoto $\mathrm{P}$, Contador I. The role of stress in drug addiction. An integrative review. Physiol Behav. 2019;202:62-8.

44 Wolitzky-Taylor K, Schiffman J. Predictive associations among the repeated measurements of anxiety, depression, and craving in a dual diagnosis program. J Dual Diagn. 2019;15:140-6.

45 Carreiro S, Chintha KK, Shrestha S, Chapman B, Smelson D, Indic P. Wearable sensor-based detection of stress and craving in patients during treatment for substance use disorder: a mixed methods pilot study. Drug Alcohol Depend. 2020;209:107929.

46 Aksu MH, Sahiner SY, Sahiner IV, Koparal B, Utku C, Coşar B, et al. Relationship between somatization and psychiatric symptoms, especially anxiety, depression, alexithymia, and severity of addiction in male patients with alcohol and heroin addiction. Dusunen Adam. 2020;33:120-9.

47 Serafini K, Toohey MJ, Kiluk BD, Carroll KM. Anger and its association with substance use treatment outcomes in a sample of adolescents. J Child Adolesc Subst Abuse. 2016;25:391-8.

48 Zhang R, Volkow ND. Brain default-mode network dysfunction in addiction. Neuroimage. 2020;200:313-31.

49 Verdejo-Garcia A, Chong T, Stout JC, Yücel M, London ED. Stages of dysfunctional decision-making in addiction. Pharmacol Biochem Behav. 2018;164:99-105.

50 Ramirez-Castillo D, Garcia-Roda C, Güell F, Fernandez-Montalvo J, Bernacer J, Morón I. Frustration tolerance and personality traits in patients with substance use disorders. Front Psychiatry. 2019;10: 421.

51 Serafini K, Toohey MJ, Kiluk BD, Carroll KM. Anger and its association with substance use treatment outcomes in a sample of adolescents. J Child Adolesc Subst Abuse. 2016;25:391-8.

52 Baharvand P, Malekshahi F. Relationship between anger and drug addiction potential as factors affecting the health of medical students. J Educ Health Promot. 2019;8:157.

53 Veenstra L, Bushman BJ, Koole SL. The facts on the furious: a brief review of the psychology of trait anger. Curr Opin Psychol. 2018;19: 98-103. 
54 Puiu AA, Wudarczyk O, Kohls G, Bzdok D, Herpertz-Dahlmann B, Konrad K. Meta-analytic evidence for a joint neural mechanism underlying response inhibition and state anger. Hum Brain Mapp. 2020;41:3147-60.

55 Gilderthorp N, Wilson C, Tapp J. A psychometric evaluation of the State-Trait Anger Expression Inventory-2 for UK adult male forensic psychiatric inpatients. Int J Forensic Ment Health. 2020;19:57-67.

56 García-León A, Reyes GA, Vila J, Pérez N, Robles H, Ramos MM. The aggression questionnaire: a validation study in student samples. Span J Psychol. 2002;5:45-53.

57 Legrand AC, Price M. Emotionally valenced stimuli impact response inhibition in those with substance use disorder and co-occurring anxiety and depression symptoms. J Affect Disord. 2020;266:639-45.

58 Neale J, Kalk NJ, Parkin S, Brown C, Brandt L, Campbell AN, et al. Factors associated with withdrawal symptoms and anger among people resuscitated from an opioid overdose by take-home naloxone: exploratory mixed methods analysis. J Subst Abuse Treat. 2020;117: 108099.

59 Stohs ME, Schneekloth TD, Geske JR, Biernacka JM, Karpyak VM Alcohol craving predicts relapse after residential addiction treatment. Alcohol Alcohol. 2019;54:167-72.

60 Pridmore S, Turnier-Shea Y, Erger S, May T. The impact of cluster maintenance TMS on irritability occurring in major depressive disorder. Australas Psychiatry. 2020 Jul 28;1039856220943033. doi: $10.1177 / 1039856220943033$. Online ahead of print.

61 Makput DM. Co-occurring mental disorders among in-patients in a substance use disorder treatment center in Plateau State, Nigeria. J Biomed Res Clin Pract. 2020;3:223-9.

62 Suzuki S, Mell MM, O’Malley SS, Krystal JH, Anticevic A, Kober H. Regulation of craving and negative emotion in alcohol use disorder. Biol Psychiatry Cogn Neurosci Neuroimaging. 2020;5:239-50.

63 Volkow ND, Koob GF, McLellan AT. Neurobiological advances from the brain disease model of addiction. N Engl J Med. 2016;374:363-71.

64 Venkataraman A, Turton S, Lingford-Hughes A. Drug use and associated neuropsychiatric conditions. United Kingdom: Oxford Textbook of Neuropsychiatry: Oxford University Press; 2020.

65 Volkow ND, Koob G. Brain disease model of addiction: why is it so controversial? Lancet Psychiatry. 2015;2:677-9.

66 Votaw VR, Pearson MR, Stein E, Witkiewitz K. The addictions neuroclinical assessment negative emotionality domain among treatment seekers with alcohol use disorder: construct validity and measurement invariance. Alcohol Clin Exp Res. 2020;44:679-88.

67 Massah O, Sohrabi F, A'azami Y, Doostian Y, Farhoudian A, Daneshmand R. Effectiveness of gross model-based emotion regulation strategies training on anger reduction in drug-dependent individuals and its sustainability in follow-up. Int J High Risk Behav Addict. 2016;5:e24327.

68 Cannella LA, McGary H, Ramirez SH. Brain interrupted: early life traumatic brain injury and addiction vulnerability. Exp Neurol. 2019;317:191-201.

69 Zhang J, Lipp OV, Hu P. Individual differences in automatic emotion regulation interacting with primed emotion regulation during an anger provocation. Front Psychol. 2017;8:614.

70 Sliedrecht W, de Waart R, Witkiewitz K, Roozen HG. Alcohol use disorder relapse factors: a systematic review. Psychiatry Res. 2019;278:97-115.

71 Kashdan TB, Goodman FR, Mallard TT, DeWall CN. What triggers anger in everyday life? Links to the intensity, control, and regulation of these emotions, and personality traits. J Pers. 2016;84:737-49.

72 Wemm SE, Sinha R. Drug-induced stress responses and addiction risk and relapse. Neurobiol Stress. 2019;10:100148.

73 Wrosch C, Barlow MA, Kunzmann U. Age-related changes in older adults' anger and sadness: the role of perceived control. Psychol Aging. 2018;33:350-60.

74 Brown RL. The influence of stressor exposure and psychosocial resources on the age-anger relationship: a longitudinal analysis. J Aging Health. 2016;28:1465-87.

75 Kirsch D, Nemeroff CM, Lippard ET. Early life stress and substance use disorders: underlying neurobiology and pathways to adverse outcomes. Advers Resil Sci. 2020;1:29-47.

76 Baharvand $\mathrm{P}$, Malekshahi F. Relationship between anger and drug addiction potential as factors affecting the health of medical students. J Educ Health Promot. 2019;8:157.

77 Czermainski FR, Ornell F, Guimarães LS, Kessler F, Von Diemen L, de Almeida RM. Assessment of executive functions and inhibitory control in alcohol and crack use disorders. Psico. 2018;49:21-30.

78 Barrett EL, Mills KL, Teesson M. Mental health correlates of anger in the general population: findings from the 2007 National Survey of Mental Health and Wellbeing. Aust N Z J Psychiatry. 2013;47: 470-6. 